\title{
SERVIÇOS URBANOS EM REDE E CONTROLE PÚBLICO DO SUBSOLO novos desafios à gestão urbana
}

\author{
Ricardo Toledo Silva \\ Arquiteto e Urbanista, Professor da Faculdade de Arquitetura e Urbanismo da USP, \\ Coordenador Científico do Núcleo de Pesquisa em Informações Urbanas da USP \\ Lenira Machado \\ Socióloga, Analista da Fundação Seade
}

\begin{abstract}
Resumo: $\mathrm{O}$ artigo trata das principais atribuições de competências estabelecidas pela Constituição federal e mostra que, embora exista o apoio de princípios constitucionais para um papel pró-ativo dos municípios e das entidades supramunicipais - regiões metropolitanas, aglomerações urbanas e microrregiões -, essa ação não ocorre na prática.

Palavras-chave: gestão urbana; rede; subsolo.
\end{abstract}

$\mathrm{D}$ iscutem-se aqui os aspectos da oferta de serviços públicos em rede e do controle público do subsolo à luz da importância crucial que o acesso a esses serviços tem hoje para a inserção social dos cidadãos, o que transforma o controle do subsolo em componente central da gestão urbana democrática. Contribuem para a importância renovada desses serviços, por um lado, a sofisticação e a diversidade das redes, que emergem como elementos definidores de espaços privilegiados na cidade, e, por outro, a crescente necessidade de conexão a serviços públicos como pré-condição de obter a alternativas de emprego e renda para um número cada vez maior de atividades urbanas.

A seguir, a partir de uma análise de características de oferta dos serviços na Região Metropolitana de São Paulo e de instrumentos legais de controle do subsolo no Município de São Paulo, demonstra-se que existe um grande descompasso entre a estrutura de regulação da oferta - ainda associada a um padrão fordista de demanda - e as necessidades de um processo de inserção econômica e social mais complexo da população urbana. Nessa perspectiva, o controle público do subsolo não se afigura mais como simples componente auxiliar de gestão do espaço físico da cidade, mas como elemento necessário à promoção da justiça social no espaço urbano. Mais adiante, em uma análise sobre estrutura de oferta de serviços e segregação urbana, este texto mostra a existência de uma correlação forte entre ní- veis de acesso e indicadores sociais, inclusive emprego. No entanto, alcance efetivo dos serviços - como mostram evidências trabalhadas para a RMSP - não é detectável apenas a partir da cobertura, mas sim de uma função mais complexa de conectividade, associada às capacidades transmitidas em cada segmento da rede. Surge, então, a necessidade de um controle público mais estrito sobre a rede, que passa pelo uso do subsolo urbano.

Ao se considerarem, porém, os instrumentos legais aplicados nesse controle para o caso do Município de São Paulo, observa-se que de fato o poder público municipal está longe de exercer suas prerrogativas e mesmo de conhecer o que existe em sua jurisdição. No caso da capital, existem normas que isoladamente estabelecem o controle, mas, em seu conjunto e ligadas aos instrumentos de sua aplicação, acabam por resultar em um mero expediente burocrático, sem eficácia sobre a gestão do espaço urbano. O grande desafio que se afigura hoje, à gestão urbana democrática, é a incorporação efetiva de suas competências no processo de regulação dos serviços em rede, de maneira que os enormes potenciais de localização de oportunidades e de condições de acesso a direitos sociais aliados à estrutura de oferta desses serviços possam ser incorporados às estratégias urbanas de planejamento e gestão.

As entrevistas realizadas na Telefonica e no Departamento de Controle e Uso de Vias Públicas - Convias trou- 
xeram à baila as alternativas de gestão para o setor. A primeira pressupõe o fortalecimento do Convias dentro da estrutura da administração municipal; a segunda aventa a possibilidade de ter-se um organismo privado que se responsabilize por manter atualizada uma base georreferenciada do subsolo da cidade e de suas redes conforme modelo já utilizado em cidades dos Estados Unidos. A questão que se coloca é quem participará dessa discussão e, em decorrência, da decisão.

\section{O QUADRO URBANO ATUAL E AS COMPETÊNCIAS SOBRE OS SERVIÇOS EM REDE}

A intensa transformação pela qual têm passado as sociedades contemporâneas - ocasionada pela maior interdependência entre os países, a crise fiscal e financeira dos Estados nacionais, a maior preocupação com a questão ambiental - e a crescente demanda social trouxeram novos desafios às cidades.

No Brasil, o quadro urbano é caracterizado pela baixa qualidade de vida e pela falta de sustentabilidade das cidades. Os instrumentos impróprios de gestão urbana, aliados à insuficiência de investimentos, potencializaram os efeitos do rápido crescimento das cidades traduzidos na expressiva quantidade de moradias inadequadas, na ineficiência do sistema de transporte e na crescente agressão ao meio ambiente.

Dentre os fatores que contribuíram para tal situação, destacam-se a dificuldade de acesso ao solo urbano e a inexistência de uma política urbana voltada às necessidades da população. Um único dado comprova a amplitude do problema: cerca de $70 \%$ dos domicílios favelados no país estão localizados em áreas ocupadas informalmente. Estudo recente do Ipea mostra uma nova configuração da nossa rede urbana comandada por 111 centros urbanos, que congregam 441 municípios e abrigam mais da metade da população brasileira. Se pensarmos na extensão territorial do Brasil e no número de municípios existentes, podemos ter uma idéia precisa da concentração dos problemas que daí advêm para as administrações municipais.

Compete aos municípios - nos termos do artigo 30 da Constituição federal - organizar e prestar os serviços de interesse local, de forma direta ou indireta, por meio de concessão ou permissão, permanecendo sob sua responsabilidade as atividades de regulação e controle, próprias e indelegáveis do poder público, além de promover o adequado ordenamento territorial, mediante o controle do uso, do parcelamento e da ocupação do solo urbano. Persis- tem, no entanto, conflitos e indefinições com relação às competências, principalmente devido à falta de regulamentação dos preceitos constitucionais e à inexistência de leis federais que disponham sobre o desenvolvimento urbano. ${ }^{1}$ De modo geral, os instrumentos de planejamento e de gestão das cidades são insuficientes, especialmente por não acompanharem as transformações da realidade urbana brasileira.

Os serviços públicos em rede cada vez mais são articulados em estruturas que abrangem vários municípios, essencialmente no caso das regiões metropolitanas e aglomerações urbanas em que a integração se impõe como requisito básico de operação dos sistemas. É o caso dos sistemas metropolitanos de produção de água e de esgotamento sanitário, dos sistemas regionais de transmissão de energia elétrica e das grandes áreas de operação de telefonia fixa e móvel. Toda a organização desses serviços - desde o modelo das grandes entidades estatais de infra-estrutura dos anos 60 e 70 - tem-se pautado por modelos de gestão setorial pouco sensíveis às prioridades regionais e urbanas de ordenação do território. No processo de reestruturação institucional ora em curso, que privilegia a prestação privada desses serviços, mantém-se, no sistema regulador que emerge, a mesma lógica setorial do modelo precedente, sem quaisquer inovações no que respeita à relação com o território e aos instrumentos de sua ordenação.

Vale ressaltar que, em todos os níveis de governo, a abordagem das questões urbanas é freqüentemente setorizada, sem que haja integração e articulação (vertical e horizontal) das intervenções públicas. Mas, no nível municipal, a desarticulação das redes de serviços públicos mostra-se mais marcante, especialmente nos casos em que poderes concedentes e concessionárias são regidos por instrumentos de regulação supramunicipais.

\section{RELAÇÕES BÁSICAS ENTRE INFRA-ESTRUTURA E NECESSIDADES SOCIAIS ${ }^{2}$}

De um ponto de vista histórico, as relações entre a infraestrutura (urbana e regional) e as necessidades sociais são relativamente recentes e pouco exploradas. Os próprios sistemas de serviços públicos em rede, associados à infraestrutura, apenas passaram a ser considerados objeto de um processo de generalização de acesso a partir do início do século XX, nas principais cidades do mundo. As redes de infra-estrutura e serviços, tal como conhecidas hoje em sistemas de funções hierarquizadas, começaram a ser implantadas em meados do século XIX, mas seu alcance era 
- tanto nas cidades mais ricas da Europa e dos Estados Unidos, quanto nas capitais das ex-colônias, como o Rio de Janeiro - limitado às áreas centrais e sua oferta não era contínua. A evolução desses sistemas em direção à generalização é abordada em profundidade, dentre outros autores, por Foreman-Peck e Millward (1994) e por Rose (1995), respectivamente para os casos do Reino Unido e dos Estados Unidos.

A construção, segundo Foreman-Peck e Millward (1994), de uma perspectiva econômica fortemente relacionada à lógica da oferta mostra que a estruturação desses serviços na forma de monopólios integrados e coordenados foi a mais coerente e eficiente desde a sua formação até o final da década de 70 , em função de suas tecnologias, em geral avessas à duplicação ou segmentação associada a uma oferta competitiva. Demonstra também que os setores de infra-estrutura - incluindo transporte, comunicações, energia e água - foram absolutamente essenciais para garantir o desempenho da economia britânica em seu conjunto. Os ativos totais desses setores sempre superaram aqueles da indústria de transformação, e, de maneira geral, as redes de infra-estrutura e sua operação caracterizam uma indústria de capital intensivo. Apesar disso, os serviços em rede podem, em diferentes situações, ser ofertados a custo marginal bastante baixo, o que certamente facilita sua generalização pelo lado da demanda para reprodução social. De certa forma, a grande procura para produção tornou viável a oferta de serviços a custos marginais mais baixos para a reprodução social - em que pese os elevados custos médios decorrentes das necessidades iniciais de grandes investimentos -, contribuindo para o processo de generalização do acesso.

A concepção de Rose (1995), a partir de uma perspectiva mais urbana e social da evolução da infra-estrutura e dos serviços em rede, mostra que, do impulso predominantemente voltado à base econômica que caracterizou sua implantação nos Estados Unidos no século XIX, a disponibilidade dos serviços em rede passou a criar valores culturais específicos de uma sociedade urbana que - de acordo com o autor - passaram a ser determinantes dos movimentos da oferta. Para ele, a difusão da tecnologia de redes consumida nas cozinhas, nos escritórios e nas ruas das cidades teve influência marcante sobre os padrões de oferta e estruturação geográfica dos macrossistemas, mais que a localização dos grandes complexos industriais para os quais esses serviços constituíam insumos básicos.

Em ambas as teses, apesar da diferença de enfoque, está presente o duplo caráter dos serviços em rede com res- peito à produção econômica e à reprodução social, e, nos dois casos, a oferta prioritariamente dedicada à primeira resultou em um acesso generalizado em benefício da segunda.

No caso dos países periféricos, a expansão da infraestrutura e dos serviços em rede também foi determinada primordialmente pelas necessidades da produção econômica, com a diferença de que os excedentes ofertados não foram - na maior parte dos casos - suficientes para atender à procura para consumo. Tanto faz, nesse contexto buscar a explicação na lógica econômica da construção de Foreman-Peck e Millward (1994), fortemente associada à perspectiva da oferta, ou na lógica cultural de Rose (1995), que privilegia o lado da demanda. Provavelmente ambas explicariam, parcialmente, o limitado alcance que os serviços sempre tiveram para a maioria das populações urbanas desses países. Os custos marginais dos excedentes da demanda econômica nunca chegaram a ser tão baixos a ponto de permitir a plena generalização do acesso, e a expressão social da procura urbana nunca foi tão importante, em seu conjunto, para que determinasse um direcionamento específico da oferta no sentido de atendêla de forma generalizada. De qualquer modo, essas explicações são parciais, e o que parece ser determinante dessa baixa generalização de distribuição é o limite absoluto de capacidade de investimento na expansão da oferta. As construções britânica e americana procuram explicar o porquê da generalização, e a nossa, o porquê da não-generalização.

Qualquer que seja a explicação de fundo, o fato é que o processo de desenvolvimento da oferta de infra-estrutura e dos serviços em rede no Brasil e nos demais países latino-americanos nunca atingiu o estágio de expansão das ofertas nos países capitalistas avançados, e isso cria uma condição de base muito distinta para o estabelecimento de uma agenda de necessidades para os novos modelos de organização da oferta que lá e cá se afirmam.

Em trabalhos anteriores recentes (Silva 2000a e b), foram comentadas análises de pesquisadores britânicos acerca dos novos padrões de oferta dos serviços em rede naquele país (Guy e Marvin, 1996), segundo as quais a gestão privada havia conduzido o processo decisório para uma orientação predominante de gestão de demanda, em contraste com o modelo anterior, baseado estritamente no planejamento de oferta. Uma leitura apressada dessa tendência - que é real também nos países capitalistas periféricos - poderia levar à conclusão de que a maior sensibilidade relativamente às aspirações da demanda seria 
traduzida em maior democratização nos critérios de destinação de capacidades. Essa conclusão - eventualmente admissível no contexto de países capitalistas avançados, nos quais a oferta básica de serviços já estava satisfeita e universalizada antes da privatização - de nenhuma maneira poderia ser transposta para o contexto dos países periféricos, nos quais o lado da demanda, conserva, em seu interior, os desequilíbrios estruturais que marcam nossas sociedades como profundamente desiguais.

A visualização dessa desigualdade no espaço urbano, entretanto, não é tarefa trivial. Para isso é preciso lançar mão de instrumentos mais refinados de análise, tanto do lado das novas formas de inserção econômica e social dos segmentos populares na cidade cuja estrutura produtiva se transforma, quanto do lado da distribuição territorial de capacidades dos serviços em rede.

\section{OFERTA DE SERVIÇOS EM REDE E SEGREGAÇÃO SOCIAL}

A distribuição dos serviços em rede tem como um de seus principais indicadores a cobertura, medida em proporção dos domicílios ligados a cada serviço sobre o total de domicílios na área considerada. No entanto, esse indicador não dá conta das condições de acesso efetivo, se consideradas as quantidades e qualidades destinadas a cada segmento.

Por mais que haja defasagens de cobertura com relação aos países capitalistas avançados, abordadas na seção precedente, existe uma tendência lógica à generalização de cobertura que se verifica em muitas concentrações urbanas de países de menor renda, e a Região Metropolitana de São Paulo é exemplo nítido dessa tendência.

As redes de abastecimento público de água e de distribuição de energia elétrica estão de alguma forma presentes em praticamente todos os domicílios da Região Metropolitana de São Paulo. Isso não quer dizer, porém, que todos os domicílios obtenham qualidades e quantidades equivalentes de serviços. Em que pese a generalização do acesso básico, é notório que algumas áreas têm condições de serviço melhores que outras, seja por limitações técnicas de difícil superação - como no caso das extremidades de redes de distribuição de água, onde as pressões de serviço não atingem os mínimos necessários à garantia de continuidade de abastecimento ao longo do dia-, seja por ação deliberada de manejo operacional, que, no gerenciamento de capacidades totais insuficientes, determina prioridades de despacho.

Já em outros sistemas, cujo horizonte de generalização de cobertura é mais distante, a leitura direta das dife-

MAPA 1

Cobertura do Sistema de Abastecimento Público de Água, por Percentual de Domicílios Ligados à Rede Região Metropolitana de São Paulo - 1991

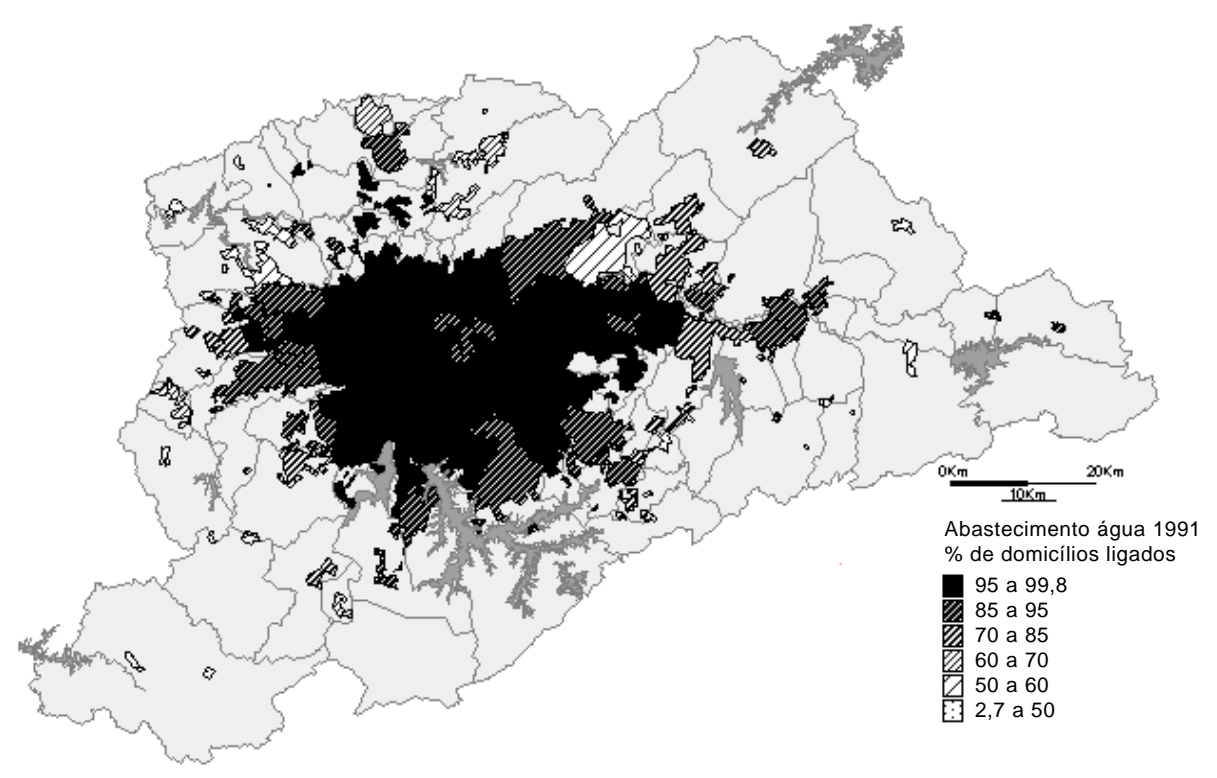

Fonte: Fundação IBGE. Censo Demográfico, 1991. 
renças relativas a domicílios ligados sobre o total em cada área proporciona uma boa aproximação das respectivas capacidades de distribuição final. É o caso, dentre outros, dos sistemas de esgotamento sanitário e de telefonia fixa, que apresentam ainda grandes desequilíbrios de abrangência entre diferentes áreas da mancha urbana. Do ponto de vista metodológico, essa constatação conduz à hipótese de que a cobertura seja uma representação aceitável de nível de acesso quando as redes e os serviços considerados estão em seus estágios ainda iniciais de expansão básica; à medida que os sistemas vão amadurecendo, essa representação já não satisfaz (Silva, 2000a).

Nos Mapas 1 e 2 são representados respectivamente os esquemas de cobertura metropolitana de rede de abastecimento de água, para 1991, e de telefonia fixa para 1997. No primeiro caso, o sistema mais maduro (água) - embora ainda mantivesse em 1991 algum desequilíbrio de alcance entre os distritos metropolitanos - apresenta uma quase homogeneidade de acesso aparente no território metropolitano.

O sistema menos maduro - que ainda não atingiu cobertura básica - de telefonia fixa deixa clara a lógica de segregação espacial e a relação nítida entre maior cobertura e renda. O Gráfico 1 representa a correlação entre acesso à telefonia fixa e à renda do chefe de família dos
132 distritos metropolitanos, em que o alto coeficiente de determinação obtido confirma enfaticamente o representado no Mapa 2.

A maior homogeneidade de abrangência dos sistemas mais maduros não significa, porém, que tenham sido superados os desequilíbrios distributivos evidenciados pela baixa cobertura dos menos maduros. Significa apenas que a cobertura já não é um indicador satisfatório de acesso e, portanto, de nível relativo de universalização. Por isso são importantes as informações complementares relativas às capacidades das redes e de seus segmentos, em uma política pró-ativa de controle do subsolo da parte das autoridades urbanas (municipais, metropolitanas e outras).

O Mapa 3 mostra esquematicamente a estrutura do sistema adutor metropolitano, que permite identificar, nas periferias do sistema, os pontos de maior vulnerabilidade potencial, a escassez e as variações de pressão, devido ao menor grau de redundância (conexão simultânea a mais de um sistema produtor).

Mesmo sem se aprofundar na análise dessa rede, é possível logo verificar que o simples fato de existir seu desenho e de este ser publicado pela concessionária metropolitana de saneamento básico já é um grande passo para tornar mais transparente a relação entre condições operacionais e qualidade do serviço prestado. O mapa da rede

MAPA 2

Cobertura da Rede de Telefonia Fixa, em Número de Linhas por 100 Habitantes

Região Metropolitana de São Paulo - 1997

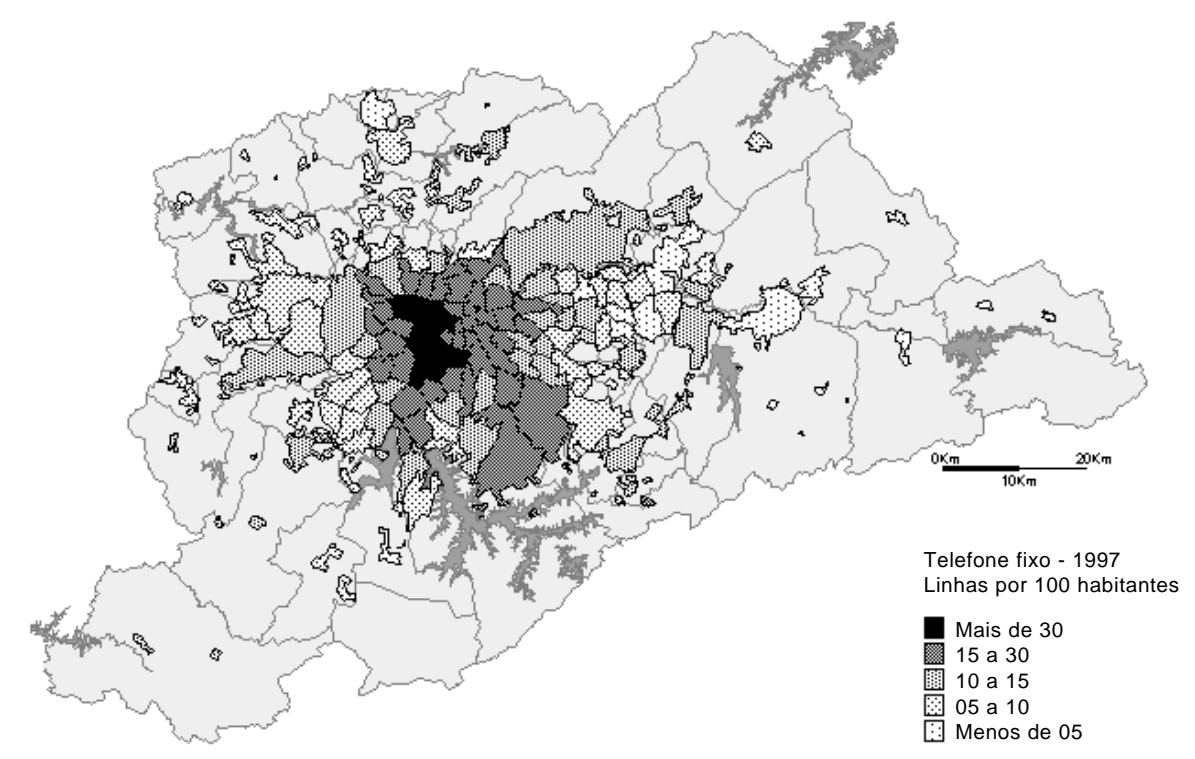

Fonte: Secretaria de Transportes Metropolitanos. Pesquisa Origem/Destino, 1997. 


\section{GRÁFICO 1}

Relação entre Cobertura de Telefonia Fixa e Percentual de Domicílios com Renda do Chefe até 2,5 Salários Mínimos Mensais Região Metropolitana de São Paulo - 1997

Renda do Chefe até $2,5 \mathrm{sm}$

Previsto(a) Renda do Chefe até $2,5 \mathrm{sm}$

Linear (Previsto(a)Renda do Chefe até $2,5 \mathrm{sm}$ )

Em \%

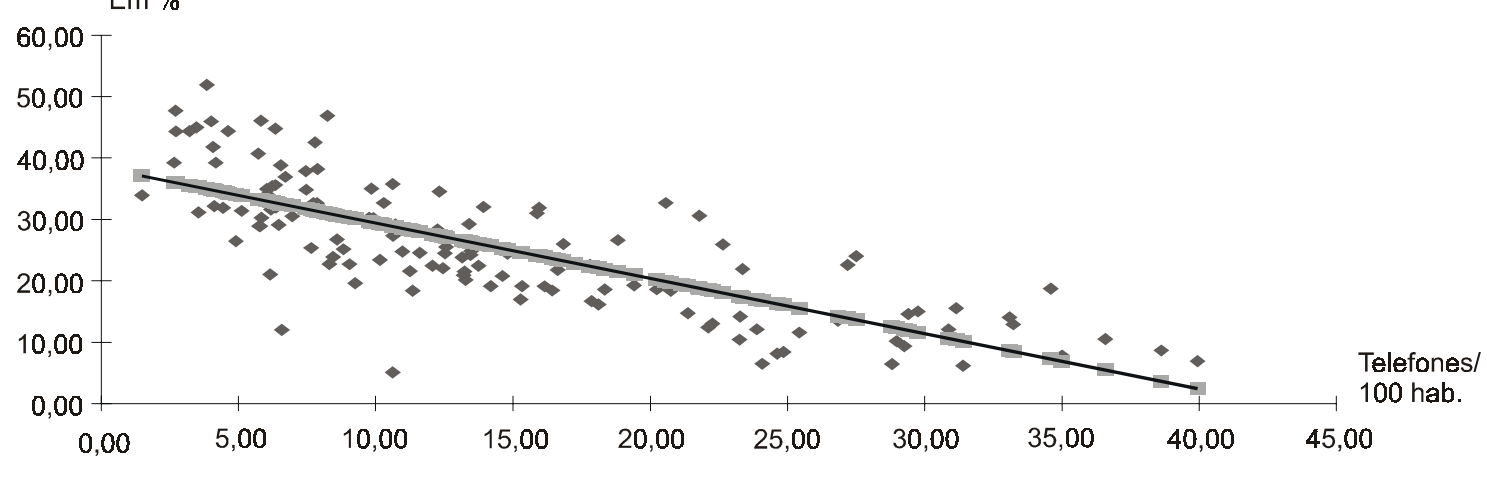

Estatística de regressão

\begin{tabular}{lr}
\hline R múltiplo & 0,776423 \\
R-quadrado & 0,602833 \\
R-quadrado ajustado & 0,599801 \\
Erro padrão & 6,718854 \\
Observações & 133 \\
\hline
\end{tabular}

Fonte: Núcleo de Pesquisa em Informações Urbanas da Universidade de São Paulo (a partir de combinação de dados da Pesquisa O/D, 1997).

\section{GRÁFICO 2}

Relação entre Cobertura de Telefonia Fixa e Número de Empregos Totais por 100 Habitantes Região Metropolitana de São Paulo(1) - 1997

- Empregos/100 hab. - Previsto(a) Empregos/100 hab. Linear (Previsto(a) Empregos/100 hab.)

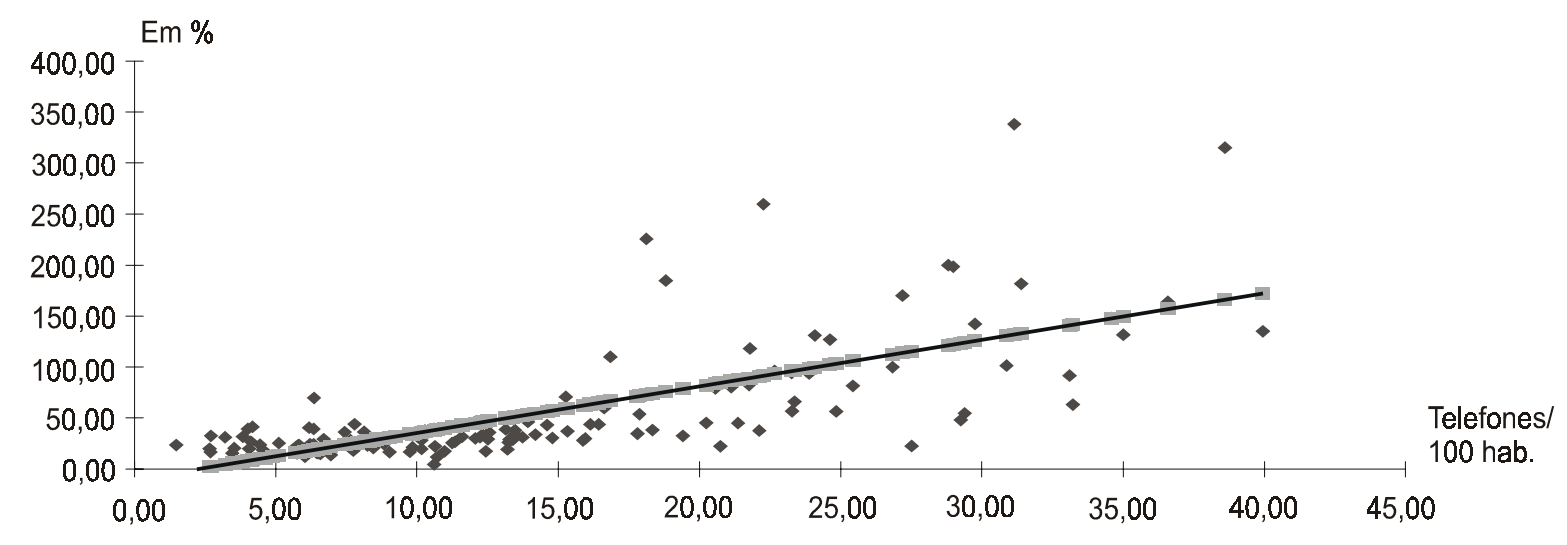

\begin{tabular}{lr}
\hline & Estatística de regressão \\
\hline R múltiplo & 0,70973 \\
R-quadrado & 0,503717 \\
R-quadrado ajustado & 0,499899 \\
Erro padrão & 41,80046 \\
Observações & 132
\end{tabular}

Fonte: Núcleo de Pesquisa em Informações Urbanas da Universidade de São Paulo (a partir de combinação de dados da Pesquisa O/D, 1997). (1) Exclui o Distrito Sé. 


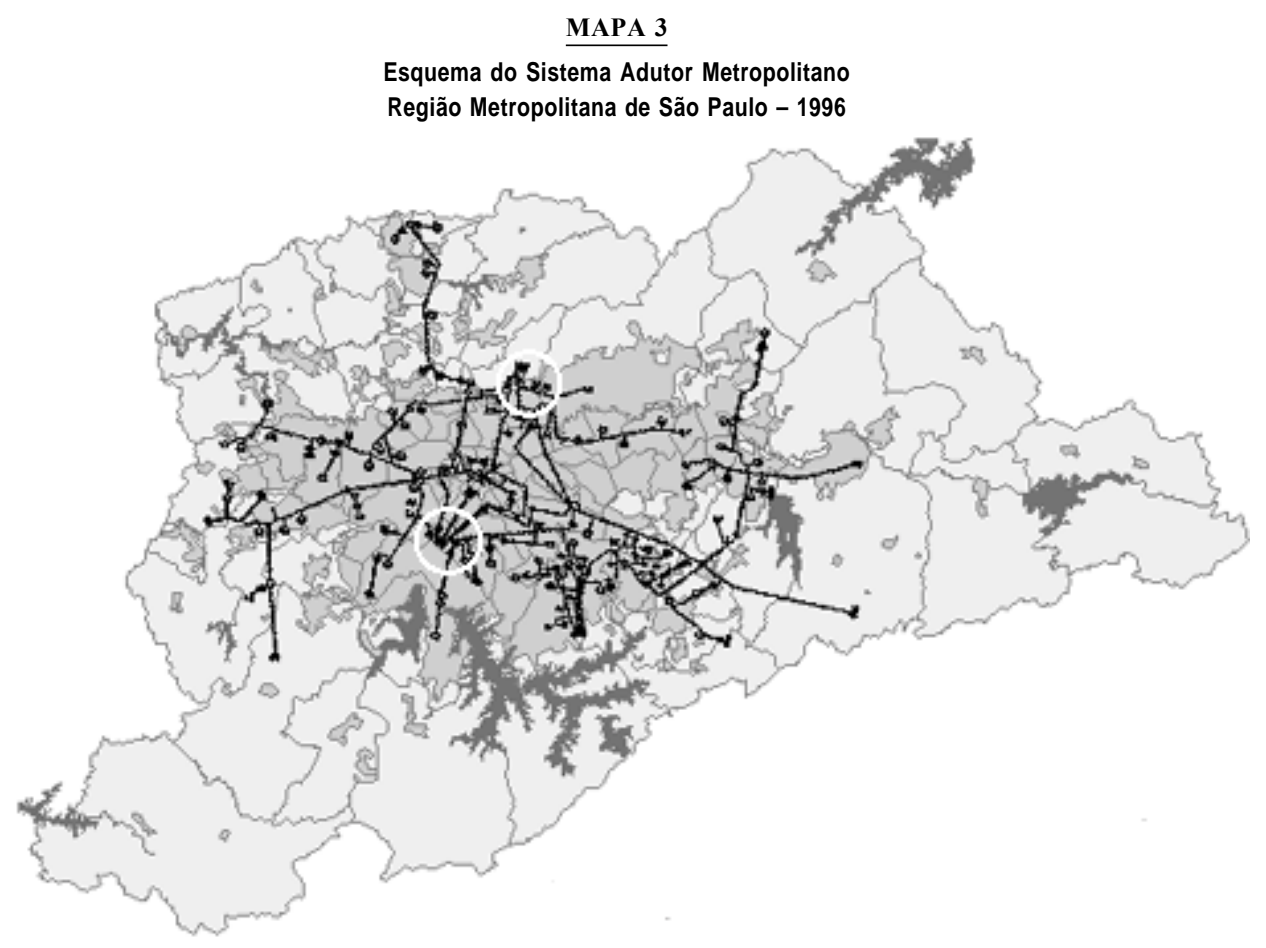

Fonte: SABESP.

permite entender diferenças de acesso que não são absolutamente vislumbradas mediante observação do mapa de cobertura. Ocorrências como rodízio de abastecimento e falta de pressão não atingem igualmente os vários distritos da metrópole, e a maior disponibilidade de informações permite que a sociedade se posicione com mais clareza sobre suas prioridades no planejamento estratégico e na gestão dos serviços que por direito lhe pertencem, a despeito de concedidos a terceiros para fins de operação.

A relação entre acesso a serviços urbanos e condições sociais sempre foi reconhecida por diferentes correntes de análise e formulação de política urbana. Não é novidade que as áreas menos servidas por infra-estrutura de saneamento básico são as que sofrem de mais problemas de saúde pública e as que abrigam os maiores contingentes de população de baixa renda. No entanto, há toda uma dimensão de inclusão social relacionada às oportunidades de geração de emprego e renda em grande parte ignorada, que também se relaciona com o acesso aos serviços em rede.

A hipótese de que os serviços públicos desempenham hoje - mais que no passado recente - um novo papel social ela passa a ser determinante na geração de oportunidades diferenciadas às suas redes, proporcionando espaços privilegiados nas cidades. $\mathrm{O}$ estudo sistemático das relações entre a localização das categorias socioo- cupacionais ${ }^{3}$ e dos nichos urbanos mais privilegiados quanto à conectividade dos serviços em rede tem um potencial enorme como apoio às políticas públicas urbanas. Esse potencial corresponde à importância cada vez mais reconhecida de que a eficácia das políticas sociais apenas se pode medir se considerados seus impactos em microescala. Os modelos de avaliação da eficácia de investimentos públicos em agregação macrorregional ou nacional (Batten e Carlsson, 1996) são válidos para detectar a conformidade a grandes objetivos de crescimento econômico, mas a avaliação de seus resultados sociais não prescinde de verificações em microescala.

A correlação entre cobertura de telefonia fixa e emprego para 132 distritos da RMSP (eliminado o distrito Sé por situação atípica quanto ao número de habitantes fixos) mostra coeficiente de determinação quase tão elevado quanto o anterior, deixando clara a interdependência entre as duas variáveis.

É evidente que apenas essas correlações brevemente comentadas neste artigo não são suficientes para comprovar a hipótese de novos padrões de demanda e, menos ainda, de possíveis relações de causalidade. Por exemplo, no tocante à interdependência verificada entre telefonia fixa e emprego terciário, pode-se argumentar que a oferta do serviço segue a concentração de demanda, e não o opos- 
to, o que certamente é verdade do ponto de vista do planejamento estratégico setorial. No entanto, a observação sobre o conjunto das condições de inserção urbana das diferentes atividades econômicas e dos grupos sociais a ela ligados sugere que existe também um forte poder indutor pelo lado da oferta dos serviços, embora ainda não plenamente conhecido em sua magnitude.

$\mathrm{O}$ entendimento desse processo e o domínio sobre variáveis-chave de indução à atividade econômica e da localização de oportunidades de emprego e renda na cidade dependem de um controle social efetivo sobre o subsolo urbano. A regulação pública sobre os serviços em rede não pode se limitar ao âmbito das disputas isoladas entre provedores e usuários nem à observância genérica dos princípios de generalidade, continuidade e modicidade de tarifas. O objetivo de universalização de acesso - reconhecido como prioritário em todo o aparato institucional que se forma em torno da infra-estrutura e serviços em rede - apenas será efetivo se associado a políticas e estratégias pró-ativas de ordenação democrática do território urbano e regional. E isso só se tornará possível se as esferas investidas de poder sobre essa ordenação forem reconhecidas como interlocutores de peso no processo regulador dos serviços.

\section{A GESTÃO DO SUBSOLO URBANO: ENTRE A LEI E A AÇÃO}

Se a gestão urbana é, como citado anteriormente, setorizada e caótica, os problemas se potencializam quando o foco passa a ser o subsolo das grandes cidades.

Tomando a cidade de São Paulo como estudo de caso por sua própria complexidade, podemos constatar que: - a preocupação com a gestão do subsolo é recente, e os mecanismos existentes mostram-se conflitantes e insuficientes;

- nem o Município nem o Estado souberam ou pretenderam utilizar as redes de serviços públicos, já existentes ou em suas expansões, como mais um instrumento de inserção da parcela da população de baixo poder aquisitivo na dinâmica social e econômica da cidade.

A partir de 1970, com a Lei Municipal n ${ }^{\circ} 7.513$, manifesta-se a preocupação em normatizar a execução de obras e serviços nas vias e nos logradouros públicos do município. Explicita-se a necessidade de aprovação prévia dos projetos e planos de trabalho para a execução de obras e serviços, porém não se determina o órgão municipal responsável por essa aprovação, e essa lei não toca nas questões referentes às formas de uso e gestão do subsolo - ela representa o formalismo burocrático da nossa administração.

Outras leis e diversos decretos são promulgados na década de 70. No entanto, não transparece a vontade política de efetivamente estabelecer regras claras para as concessionárias dos serviços públicos atuarem no manuseio do sistema viário da cidade. É ilustrativo o que ocorre com a Lei ${ }^{\circ} 8.658$, promulgada em 1977, que leva nove anos para ter seus artigos regulamentados pelo Decreto $\mathrm{n}^{\circ}$ 23.404/87. Ao serem regulamentados os artigos $6^{\circ}$ e $7^{\circ}$ dessa lei, a cidade passa a contar com normas para a aprovação de projetos que interferem nas vias públicas e, ao mesmo tempo, são definidas as competências do Departamento de Controle e Uso de Vias Públicas - Convias vinculado à Secretaria de Vias Públicas, que passa a ser responsável pela "autorização dos equipamentos e utilização das vias e logradouros públicos explicitando que os serviços de infra-estrutura urbana, prestados por entidades de direito público e privado, obrigatoriamente atenderão aos dispositivos deste decreto e demais atos normativos" (Decreto n ${ }^{\circ}$ 23.404/87).

Além disso, cabe ao Convias aprovar o planejamento das obras e organizar o cadastro de instalações e equipamentos existentes e os que vierem a ser instalados. Ao mesmo tempo, o decreto possibilita a descentralização das ações ao permitir que outros órgãos da administração municipal autorizem a execução das obras, desde que:

- o interessado apresente a aprovação técnica ou liberação da obra emitida pelo Convias;

- o órgão fiscalizador da execução da obra ou do serviço se obrigue a comunicar ao Convias o início e o fim dos trabalhos, atestando se a implantação das obras respeitou o previsto no projeto em relação ao posicionamento da rede em toda sua extensão.

Tendo em vista a alimentação permanente e a atualização do cadastro, organizado em banco de dados de acesso comum a todos os interessados, é também prevista no decreto a celebração de convênios entre o Convias e as entidades de direito público e privado que tenham equipamentos já implantados.

As Portarias 24 e 107 de 1988 emitidas pelo secretário de Vias Públicas, consoante o decreto acima analisado, buscam disciplinar a reserva de espaços nos subleitos das vias públicas e a utilização de viadutos, pontes e pontilhões pelos equipamentos dos serviços de infra-estrutura urbana de responsabilidade das diversas concessionárias. Algumas questões relevantes são tratadas nessas portarias. A primeira refere-se à tentativa de disciplinar a extensão 
de redes no processo de expansão urbana, e a segunda busca o controle da utilização das obras de arte (pontes, viadutos e pontilhões) numa tentativa de disciplinar também o uso do espaço aéreo urbano. Dessa forma, ampliase a área de atuação do Convias, que passa a ser responsável pela gestão do uso do solo, do subsolo e do espaço aéreo da cidade. No entanto, as portarias, em seu conjunto, na prática diluem o poder do Convias ao transferir para as administrações regionais a responsabilidade de receber as solicitações das concessionárias para autorização municipal, no que concerne à implementação de projetos de suas redes. Cabe aqui uma indagação: o circuito burocrático criado pelas portarias favorece ou não o processo de planejamento urbano?

Fica claro o esvaziamento do Convias e o Decreto $\mathrm{n}^{\circ}$ 27.335 de 1985 - que em seus 28 artigos enfoca a garantia do trânsito na malha viária da cidade - explicita essa decisão política. Há um aumento das atribuições da Secretaria das Administrações Regionais nesse âmbito de atuação e surge um novo ator, o Departamento de Operação do Sistema Viário - DSV -, que passa a ser o órgão responsável pela autorização de execução das grandes obras e/ou dos serviços de grande porte das redes de água, esgoto, gás, linhas de dutos e caixas subterrâneas para telefonia, canalizações de energia elétrica e obras metroviárias. O Departamento de Controle e Uso de Vias Públicas - Convias - não é citado uma única vez no corpo do extenso decreto.

A questão da ocupação e do uso das vias públicas (subsolo, solo e espaço aéreo) pelas concessionárias é administrada de forma cíclica e avança ou retrocede conforme a dinâmica própria da burocracia. Uma análise comparativa da legislação municipal sobre o assunto poderá trazer à tona o contraditório e os conflitos existentes.

O Convias surge, é fortalecido, praticamente desaparece e, como fênix, ressurge num decreto ou numa portaria do administrador de plantão. Acompanhar esse processo permite uma visão da ausência de planejamento e da descontinuidade administrativa.

As portarias da Secretaria de Vias Públicas, a partir de 1989, estão mais voltadas aos problemas emergentes da cidade. Elas tratam de disciplinar a extensão de redes de infra-estrutura no Fundo de Vales e Cadastro do Sistema de Drenagem da cidade.

No ano de 1992 são tomadas algumas medidas visando à recuperação do planejamento na área. É constituída a Comissão de Entendimento das Concessionárias e são aprovadas as Especificações Técnicas para a execução de
Cadastro de Drenagem, o que recoloca a questão do planejamento e da autorização de uso do espaço urbano pelas redes de infra-estrutura e recupera para o Convias o papel de órgão normativo.

No entanto, a partir do Decreto no 37.553 de 1998, novamente o Convias perde espaço na administração municipal, e as autorizações para execução de obras das concessionárias passam a ser expedidas pelas administrações regionais, ouvido o Departamento de Operação do Sistema Viário - DSV.

Finalmente em 1999 o executivo municipal toma consciência de que o uso das vias públicas, inclusive do espaço aéreo, do subsolo e de obras de arte de domínio municipal pode se transformar em mais uma fonte de renda para os cofres públicos. O Decreto ${ }^{\circ} 38.139 / 99$ estipula que a utilização desses bens públicos do município deverá ser feita pelas concessionárias a título precário e oneroso. Para que isso ocorra, são necessárias outras medidas que, em tese, garantam a eficiência da administração municipal. O decreto recupera a capacidade técnica do Convias para análise e aprovação dos projetos, para a lavratura do Termo de Permissão de Uso e para o recebimento da caução da entidade pública ou privada interessada, além daquelas atribuições referentes ao cadastramento das redes de infra-estrutura. As atividades de fiscalização da execução das obras passam a ser descentralizadas. O Valor Mensal $(\mathrm{Vm})$ da contribuição pecuniária pela utilização das vias públicas, inclusive espaço aéreo, subsolo, e obras de arte será calculado conforme expressão detalhada no artigo $9^{\circ}$ do decreto em pauta. A Portaria $n^{\circ}$ 007/2000 da Secretaria de Vias Públicas estabelece as Normas para Apresentação dos Elementos de Cadastro de Equipamentos Instalados.

No processo de aproximação com o tema foram feitas duas reuniões. A primeira deu-se com a Diretoria de Planejamento da Telefonica quando tomou-se conhecimento da magnitude da utilização do subsolo da cidade, uma vez que somente essa concessionária tem mais de 90 estações de distribuição com uma rede de aproximadamente $10 \mathrm{mil}$ quilômetros de extensão. Há uma indagação a ser feita, não se sabe a quem: qual é a malha de dutos e qual a faixa de ocupação do subsolo da capital, das regiões metropolitanas e das grandes cidades paulistas? Ao que tudo indica essas informações não existem. Ao mesmo tempo constata-se que há um corpo técnico nas concessionárias e na administração pública sensibilizado pela magnitude do problema e que busca, em parceria, caminhos para superálo. O Estudo de Zoneamento do Subsolo, elaborado no 
final da década de 80 , é um marco dessa preocupação comum, e hoje, após o decreto que prevê a cobrança de utilização por faixa de ocupação, pela prefeitura, foi constituída a Comissão de Entendimento entre as Concessionárias na busca de formas de equacionamento dos conflitos existentes.

Em reunião no Convias estava, de um lado, a equipe técnica preparada e capaz de responder às questões levantadas, e, de outro, a precariedade das condições de trabalho disponibilizadas pela administração municipal para que esse corpo técnico pudesse atuar. Algumas questões básicas foram abordadas nessa reunião:

- o subsolo da cidade deve ser visto como um bem público e sua utilização é limitada e repleta de condicionantes;

- são as agências nacionais, criadas pelo governo federal, que determinam as normas de atuação das grandes concessionárias;

- o município deve estar voltado ao controle de qualidade das formas de utilização das vias, do subsolo e do espaço aéreo da cidade. Trata-se de um controle do espaço físico gerenciando a implicação de uma rede com outras redes e suas interfaces com as obras viárias;

- as primeiras permissões só ocorreram após o Decreto $\mathrm{n}^{\circ} 38.139$, ou seja, setembro de 2000 , e em quatro meses gerarem uma receita significativa (em torno de sete milhões de reais). Vale lembrar que o setor de saneamento básico é isento de pagamento da taxa de utilização do subsolo para sua rede;

- o Convias não dispõe de base cartográfica georreferenciada para o cadastro das redes de infra-estrutura;

- o desenvolvimento tecnológico, principalmente na área de informação, faz com que aflorem novas situações para serem gerenciadas. É o caso das redes corporativas: como qualificá-las? Podem ser consideradas um serviço público?

- outros órgãos municipais atuam no gerenciamento do subsolo urbano e não há quem tenha a visão global de seu uso e ocupação. Alguns equipamentos envolvem, inclusive, questões de segurança, como, por exemplo, a autorização de instalação de postos de gasolina e garagens subterrâneas;
- os processos desapropriatórios para alargamento de vias podem ser outra fonte de risco para a cidade. O caso da Avenida Paulista é emblemático, e o Contru, para contornar o problema, solicitou ao Corpo de Bombeiros vistoria semanal dos chamados "vazios" do subsolo da Paulista.

Diante da complexidade e da magnitude do problema, mal se tangenciou o cerne da questão do gerenciamento das redes. O desafio está colocado, na esperança de contribuir para que outros técnicos se interessem pelo tema.

\section{NOTAS}

1. Quando o artigo foi escrito, o Estatuto da Cidade não havia sido aprovado.

2. O texto desta seção é parte de revisão bibliográfica realizada no processo de pesquisa do Infurb/USP em cooperação com o Ippur/UFRJ, no projeto Metrópoles: desigualdades e governança urbana. Rio de Janeiro, São Paulo, Belo Horizonte e Porto Alegre, integrante do Pronex.

3. As categorias socioocupacionais consideradas nos estudos do Infurb sobre essa linha são as definidas por Ribeiro (2000) no âmbito da pesquisa Metrópoles: desigualdades e governança urbana. Rio de Janeiro, São Paulo, Belo Horizonte e Porto Alegre, citada anteriormente.

\section{REFERÊNCIAS BIBLIOGRÁFICAS}

BATTEN, D.F. e CARLSSON, C. (eds.) Infrastructure and the complexity of economic development. Nova York, Springer-Verlag, 1996.

DIÁRIO OFICIAL DO MUNICÍPIO. Leis n ${ }^{\text {os }} 7.513 / 70 ; 8.106 / 74 ; 8.658 / 77 ; 9.413$ / $81 ; 10.315 / 87 ; 10.365 / 87 ; 10.508 / 88 ; 10.544 / 88$. Decretos $n^{\text {os }} 15.086 / 78$; $15.704 / 79 ; 15.705 / 79 ; 16.724 / 80 ; 23.404 / 87 ; 27.335 / 88 ; 37.553 / 98 ; 38.139 /$ 99. Portarias n ${ }^{\text {os }} 24 / \mathrm{P} / 88 ; 107 / \mathrm{P} / 88 ; 47 / \mathrm{SVP}-\mathrm{G} / 89 ; 39 / \mathrm{SVP}-\mathrm{G} / 92 ; 40 / \mathrm{SVP}-\mathrm{G} /$ 92; 221/SVP-G/92; 001/SVP/SAR/96; 4.131/SAR-GAB/99; 007/SVPG/2000.

FOREMAN-PECK, J.F. e MILLWARD, R. Public and private ownership of British industry 1820-1990. Oxford, Clarendon Press, 1994.

GUY, S. e MARVIN, S. "Transforming urban infrastructure provision - the emerging logic of demand side management." Policy Studies, 17, 2, 1996, p.137-47.

RIBEIRO, L.C.Q. "Cidade desigual ou cidade partida? Tendências da Metrópole do Rio de Janeiro.” In: RIBEIRO, L.C.Q.(org.). O futuro das metrópoles: desigualdades e governabilidade. Rio de Janeiro, Revan, 2000, p.63-98.

ROSE, M.H. Cities of light and heath. Domesticating gas and electricity in urban America. The Pennsylvania State University Press. University Park, PA, 1995.

SABESP - Companhia de Saneamento Básico do Estado de São Paulo S/A Ecossistema São Paulo. São Paulo, Sabesp, 1996.

SANTOS, C.N.F. dos. O uso do solo e o município. $3^{\text {a }}$ ed. Rio de Janeiro, Instituto Brasileiro de Administração Municipal (Iban), 1990.

SECRETARIA DE ESTADO DE DESENVOLVIMENTO URBANO (SEDU) Presidência da República. Plano de ação para o desenvolvimento urbano. Brasília, jul. 1999.

SILVA, R.T. "The connectivity of the infrastructure networks and the urban space of São Paulo in the 90s". International Journal of Urban and Regional Research. v.24/1, 2000a, p.139-64.

"A conectividade das redes de infra-estrutura e o espaço urbano de São Paulo". In: RIBEIRO, L.C.Q.(org.). O futuro das metrópoles: desigualdades e governabilidade. Rio de Janeiro, Revan, 2000b, p.407-32. 